\title{
LITERATURA, HISTORIA Y PSICOLOGÍA EN LA OBRA DE E.L. DOCTOROW
}

Ramón León

\section{Resumen}

Uno de los más importantes novelistas norteamericanos del siglo veinte, E. L. Doctorow ha legado doce novelas. El libro del Daniel y Ragtime están entre ellas. El libro de Daniel reconstruye la atmósfera del maccartismo en los Estados Unidos de los años 1950. Esta novela está basada en el controversial caso de Julius y Ethel Rosenberg, dos civiles judios y comunistas quienes fueron juzgados y sentenciados a muerte por supuestas actividades de espionaje en 1953. Ragtime, un best-seller, retrata al New York a comienzos del siglo veinte. Este ensayo presenta una breve biografia de Doctorow y comenta su obra literaria. Las rasgos de su obra (New York como es escenario de buen número de sus novelas, su preferencia por sucesos históricos y la manipulación de personajes históricos para la trama de sus obras) son presentados y discutidos.

Palabras clave: Doctorow; Literatura; Psicología.

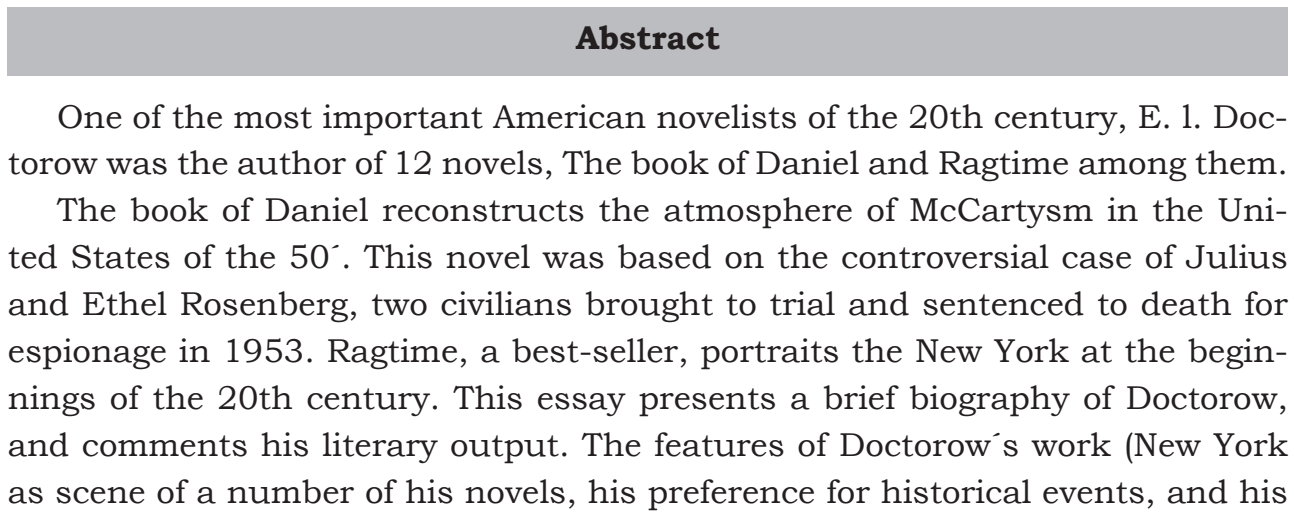


manipulation of historical personages for the plot of his novels) are also showed and discussed.

Keywords: Doctorow; Literature; Psichology.

Todos lo sabemos: cada año que pasa nos deja su penosa cosecha de muertes de personalidades de la política, del mundo del arte y de la ciencia. No faltan por supuesto, las de grandes deportistas.

Por lo general solo reciben atención internacional la de los políticos, los científicos y los artistas. No importa el lugar en el que nacieron y vivieron: la muerte de Nelson Mandela como la de Adolfo Suárez fueron objeto de comentarios y noticias en todo el mundo. Lo mismo sucede con la de famosos músicos (Leonard Bernstein, por ejemplo) y con grandes literatos, como acaba de ocurrir con E. L. Doctorow, cuya desaparición fue informada por diarios del mundo entero, que no escatimaron comentarios laudatorios acerca de su obra.

E1 fallecimiento de E. L. Doctorow ${ }^{1}$, acaecido el 21 de julio del 2015, es una pérdida irreparable para la literatura norteamericana. No tan conocido como Philip Roth o Don DeLillo ni tan audazmente original como Thomas Pynchon, o tan torrencialmente productivo como Carol Joyce Oates, este escritor deja como legado una importante obra literaria, reconocida $y$ reiteradamente premiada $^{2}$, analizada y comentada en numerosos estudios (véase por ejemplo Parks 1991, Bloom 2004).

Nacido en 1931 en New York, en el seno de un hogar de descendientes de emigrantes judios rusos, Doctorow -lector voraz ya en la niñez- se entregó desde su juventud a la creación literaria: tras un par de obras que recibieron en su momento una acogida positiva pero difusión limitada, The book of Daniel (1971) y Ragtime (1975) lo ubicaron desde los años 1970 en la galería de los grandes literatos estadounidenses de la segunda mitad del siglo XX.

No es posible tratar acá de las doce novelas que él escribió ${ }^{3}$. Solo nos dedicaremos a dos o tres. Sí podemos, empero, decir que después de The book of Daniel y Ragtime, Doctorow prosiguió su obra literaria dando a la luz, entre lo más destacado de su producción, World's fair (1985), una mirada al New York de los dificiles años treinta a través de los ojos de un niño; The march (2005), relato del avance sangriento del General Sherman al frente de sus tropas en los años postreros de la Guerra de Secesión; Homer y Langley (2009), basada en la alucinante vida de los hermanos Collyer que vivieron en la metrópoli neoyorquina, y Andrew's brain (2014), su última obra, en cuyas páginas un neurocientífico reflexiona acerca de su pasado, sus temores y sus traumas.

Doctorow fue, en alguna medida, un autor de culto. Como ya dijimos, era menos conocido que Roth y DeLi1lo, y los lectores que lo seguian debían tener paciencia a la espera de su 
siguiente libro. Su apellido, poco frecuente y de inconfundibles raíces eslavas, era causa de que algunos desinformados lo imaginaran ruso $\mathrm{y}$, al hacerlo, dejaran de lado la lectura de sus obras, porque para ellos, después de Tolstoy, Dostoievski y Pasternak, todo lo que Rusia pudiera ofrecer en materia literaria estaba cumplido. Es probable, asimismo, que su posición politica, de izquierda y contestataria, fuera causa de la poca prensa propagandística que recibió ${ }^{4}$.

Sin embargo, sus seguidores valoraban en sus libros la recreación de hechos significativos de la historia norteamericana, sazonada por su fértil imaginación y trabajada con perseverancia hasta forjar personajes claramente delineados y dotados de una vida afectiva expuesta con coherencia.

En toda obra literaria los sentimientos son la clave. Todo gran literato (Dostoievski por ejemplo, pero también Balzac y Flaubert, así como Tolstoy y, por supuesto, el propio Shakespeare) es también un gran psicólogo. No, ciertamente, un psicólogo con formación académica y certificaciones profesionales, sino un imaginativo, incisivo y acertado escudriñador de los afectos, fantasias, manías y obsesiones que pueblan y dan vida a nuestro mundo interno.

Por eso, psicólogos y psiquiatras consideran a muchas novelas y obras teatrales como verdaderos estudios de caso. Crimen y castigo estudia en detalle la culpa y el remordimiento; Hamlet disecciona la indecisión paralizante. Oblomov, del entre nosotros poco co- nocido Goncharov, es un adelanto de lo que hoy los psicólogos llaman procastinación. La muerte de Virgilio, de Hermann Broch, se concentra en el momento final de la existencia.

La fauna humana, en toda su grandeza como en toda su miseria y comicidad, ha sido retratada por los literatos de raza. Pícaros (El lazarillo de Tormes), amas de casa enloquecidas ( $E l$ diario de Edith, de Patricia Highsmith), obsesos sexuales (El mal de Portnoy, de Philip Roth), personajes en los cuales la sabiduría parece esconderse detrás de la estupidez (Las aventuras del buen soldado Svejk, de Jaroslav Hasek). Y, por supuesto, $\operatorname{locos}^{5}$. A todos ellos y a muchos más los encontramos en novelas y obras de teatro ${ }^{6}$.

El francés Antoine de Rivarol (2012) afirmaba que una palabra es solo una reunión de letras. Hay mucho de realidad, pero también mucho de escepticismo y cinismo en esa afirmación. Siguiendo su lógica, podría decirse que una novela es solo un inmenso conjunto de palabras.

Si así fuera, si la novela fuera tan solo palabras reunidas, tendría que llamarnos a asombro que la acumulación de nombres y pronombres, adverbios, sustantivos, conjunciones y verbos en diferentes tiempos, acumulación dispuesta por la mano del escritor y guiada por las imágenes que pululan en su cerebro, termine dando lugar a una obra en la que lo más humano de la condición humana (es decir, los sentimientos, las pasiones, las ilusiones, esperanzas y desengaños) es expuesto de un modo tal que 
ilumina nuestra vida (o a veces hasta la cambia de manera radical).

Y es que, como dice Pamuk (2009), [...] las palabras y la literatura son como las hormigas y el agua: las palabras se meten ante todo y de la mejor manera por los huecos, por los agujeros y por las grietas invisibles. $\mathrm{Y}$ todo lo que de verdad queremos saber sobre la vida y sobre el mundo, aparece primero en esas grietas invisible y es la buena literatura la que antes 10 ve (pg. 134).

¿Qué sentimientos aparecen en las obras de Doctorow?

En The book of Daniel, el protagonista (Daniel Lewin Isaacson, un estudiante de la Universidad de Columbia) reflexiona acerca del destino de sus padres, acusados, procesados y ejecutados por cargos de espionaje ${ }^{7}$. La rememoración pone de manifiesto la sensación de haber sido (sus padres y él) víctimas de una terrible injusticia. El dolor, el duelo, la cólera y la impotencia ensombrecen la vida de Daniel. Se percibe asimismo su ambivalencia con respecto al activismo político de sus progenitores, que habría de llevarlos a su desgraciado final. Una experiencia no menos traumática, la del intento de suicidio de su hermana, es el detonante de las reflexiones de Daniel (De Rosa, 2009).

Publicada cuando Doctorow se desempeñaba como Visiting Author en la Universidad de California (Irvine), The book of Daniel surgió como proyecto en la década de los 1960, caracterizada por intensos conflictos en torno a la participación militar de Estados Unidos en la guerra de Viet Nam y por el activismo a favor de los derechos humanos ${ }^{8}$. Esa complicada década (marcada a fuego además por el asesinato de John F. Kennedy) estimuló la aparición de algunas obras que tienen a los problemas sociales vividos en esos años como escenario en el cual se mueven los personajes. Una de ellas fue precisamente The book of Daniel; otra fue them de Carol Joyce Oates (1969).

Doctorow retrata en este libro una época de histeria colectiva y de paranoia llevada a extremos inimaginables: nos referimos al macartismo, ese "sórdido e irracional frenesí de la caza de brujas anticomunista”, como lo calificara Hobsbawm (1996), que campeó en los Estados Unidos de los años 1950. Un personaje mediocre, Joseph MacCarthy, el "senador caza-rojos de Wisconsin" (Talbot, 2008), da nombre a esta época oscura de la historia norteamericana, estimulando temores, suspicacias y pálpitos de conjuras al más alto nivel.

Virtualmente poseído por un anticomunismo febril, MacCarthy creyó ver conspiradores y enemigos de los Estados Unidos aún en las más altas esferas gubernamentales de su país. Sus delirios infectaron a buena parte de la sociedad norteamericana de los años 1950, desatando una verdadera cacería de comunistas ${ }^{9}$. Nadie estaba libre de sospechas ${ }^{10}$.

Sin duda, todo un tema para historiadores, psicólogos y sociólogos. 
Los padres de Daniel, Paul y Rochelle Isaacson, son personajes inspirados en Julian (1918-1953) y Ethel Rosenberg (1915-1953), un matrimonio norteamericano que -efectivamentefue acusado y ejecutado en 1953 por supuestas actividades de espionaje ${ }^{11}$.

The book of Daniel parece haber cumplido una función catártica para Doctorow, quien consideraba la ejecución de los Rosenberg como un hecho absolutamente injustificable, un verdadero crimen. Doctorow reaccionó ante esta injusticia del modo en que él mejor podía hacerlo: a través de la escritura.

El psicólogo familiarizado con la obra de Doctorow y conocedor de la historia de los Estados Unidos en la segunda mitad del siglo XX podrá no solo apreciar la calidad literaria de The book of Daniel, sino también, en una lectura inter lineas, reconocer (o al menos intuir) cómo el autor da curso a la intensidad de sus sentimientos en torno a la ejecución de los Rosenberg.

En efecto: la escritura es una forma de elaborar intensas experiencias emocionales, dándoles forma y sentido y construyendo una narrativa que le permite al autor comprender y contextualizar lo sucedido. Desde las Confesiones de San Agustín, hasta nuestros dias, pasando por The anatomy of melancholy, de Robert Burton, podemos encontrar obras que han tenido una función catártica para sus autores ${ }^{12}$. Gérard de Nerval y Rainer Maria Rilke pueden mencionarse como ejemplos de escritores que conjuraron vía sus obras sus grandes problemas psicológicos.
Si los judíos y comunistas son los protagonistas de The book of Daniel, en Ragtime lo son los negros, eternos marginados y maltratados en la sociedad norteamericana.

En Ragtime, Coalhouse Walker Jr., un pianista de raza negra víctima de maltratos, es ganado por el resentimiento al reconocer que la justicia norteamericana no es valedera para él, e ingresará a una senda delictiva que lo llevará a una violenta muerte. Doctorow nos introduce en la subjetividad de él, un negro que parece haber alcanzado el éxito en una sociedad tan profundamente racista.

Aceptado en la casa de una familia blanca,

[...] no se sentía embarazado por encontrarse en el salón con una taza y un plato en su mano. Por el contrario, actuaba como si fuera la cosa más natural del mundo. Lo que le rodeaba no le asustaba ni una adoptaba una actitud deferente. Era cortés y correcto. Les habló de sí mismo. Era un pianista profesional y estaba ahora más o menos permanentemente en New York, gracias a que tenía un trabajo fijo con la Jim Europe Clef Club Orchestra, un conjunto muy conocido que daba conciertos regulares en el Manhattan Casino de la Calle 155 y la Avenida 8 (Ragtime, versión castellana, pp. 196-197).

De pronto, Coalhouse Walker Jr. se ve confrontado con la realidad injusta de su condición racial en la sociedad 
estadounidense. A partir de ese momento, su destino cambia.

Doctorow avanza en el relato de la vida y muerte de este personaje, al par que nos entrega un colorido mosaico del New York de inicios del siglo XX.

New York no solo es una ciudad; tampoco es "solo" una gran ciudad". New York es una realidad convertida en mito, alimentado por todo lo que ocurre en sus calles y plazas, en sus amaneceres y crepúsculos. En esa ciudad todo puede suceder, y todo lo que sucede en ella tendrá consecuencias en la vida de los norteamericanos y todos los pobladores de la tierra, como lo demuestra la Gran Depresión y el atentado al World Trade Center.

New York ha sido idealizada, estudiada, maldecida. Pocas ciudades como ella han servido de escenario para historias doradas o sombrias, como lo demuestran las numerosas películas que la tienen como telón de fondo. Mencionemos solo algunas: King Kong (1933), West Side story (1961), Mientras Nueva York duerme (1956), Taxi Driver (1976), New York, New York (1977).

World's fair es un retrato de la metrópoli neoyorquina en los años de la feria mundial celebrada en $1939^{14}$. El protagonista Edgar Altschuler, un niño, conduce a los lectores tanto por la feria como por los ámbitos sombrios de su propia familia. Otras voces presentes en esta obra muestran algunos aspectos no muy gratos de la urbe norteamericana ${ }^{15}$.

Se trata casi de una biografía de Edgar, quien crece en el barrio de
Bronx, el mismo en el que vivió el autor, quien reconoce que esta novela "es muy cercana -sobre todo en la primera mitad- a cómo fue mi infancia" (Doctorow 2014).

En alarde de capacidad expositiva, Doctorow describe las percepciones propias de un niño. Así se presenta Edgar infante al lector:

Me despiertan sobresaltado los vapores amoniacales y paso en un instante de un sueño pegajoso a un saber afligido: he vuelto a hacerlo. Mis muslos empapados me pican. Lloro y llamo a mamá sabiendo que tendré que soportar su dura reacción, que pasar por aquello para ser rescatado. Mi cuna está en la pared este de su habitación, la de ellos en la pared sur ( $\mathrm{La}$ feria del mundo, pg. 10).

Siguiendo a Edgar conoceremos al resto de la familia, Rose y Dave sus padres, Donald el hermano mayor, la abuela materna y la tía Frances, entre otros, que cobran vida en las innumerables descripciones de la vida familiar en sus dias agradables como en sus momentos difíciles.

Un hecho interesante es que esta novela, aparte de estar ambientada en New York, tiene como época los años 30. Guijarro González (2001) escribe sobre el particular:

De nuevo Doctorow sitúa la acción durante la época de la Depresión, un momento de la historia de Estados Unidos que también habia aparecido de modo intermitente en El libro de 
Daniel y que volvería a resultar crucial en Billy Bathgate. Todas estas circunstancias ponen de manifiesto que, del mismo modo que Nueva York es el marco espacial predilecto de Doctorow, la década de los treinta es su periodo favorito. Ello obedece a varias razones simultáneamente: en primer lugar al hecho de que la infancia de Doctorow (que nació al inicio de la década en 1931) transcurrió en esos años, pero también a que para un escritor de ideología progresista como él la época de la Depresión resulta atractiva no solo por haber sido un momento de crisis en el que se cuestionaron algunos mitos fundacionales de la nación, sino también porque en ese periodo surgió una literatura social encarnada por autores como John Dos Passos o John Steinbeck con los que Doctorow se identifica (40).

New York, en medio del esplendor que irradia la Feria, tal como es visto y vivenciado por un niño. Van der Merve \& Bekker (2015) establecen una comparación entre World's fair y The adventures of Augie March, de Saul Bellow (1953), un autor que fue muy importante para Doctorow. Augie March también relata sus experiencias adolescentes, pero no en New York sino en Chicago, otra de las ciudades-mito de los Estados Unidos.

No solo cosas grandiosas ocurren en New York, sin embargo. También hay contextos y existencias que se asoman al mundo de la psicopatología.

Homer y Langley se concentra en la vida de un par de hermanos residentes en New York. Basada en personajes y circunstancias reales, esta novela expone un cuadro psicopatológico: el de la silogomanía (Medrano, 2011), la tendencia irrefrenable a acumular cosas inservibles. Homer y Langley viven encerrados en una casa y a lo largo de los años de su voluntario aislamiento han acumulado en la casa innumerables rumas de periódicos y de objetos carentes de utilidad. El caso, que en la realidad atrajo la atención del periodismo, es trabajado literariamente por Doctorow.

¿Amor, obsesión, simple casualidad, como la razón de Doctorow para elegir a New York? En una entrevista justificó del modo siguiente esa elección:

Nueva York siempre ha sido el punto de contacto entre el viejo y el nuevo mundo. Cuando yo era niño, no dejaban de llegar a la ciudad refugiados prominentes que huían de la Europa de Hitler -actores, compositores, escritores, científicos, pintores, psicoanalistas y filósofos- que enriquecieron nuestra cultura de un modo desproporcionado a su número. Por ejemplo, el compositor húngaro Bela Bartok $\mathrm{y}$ el teólogo Paul Tillich vivieron en Manhattan; Brecht o Hannah Arendt pasaron aquí temporadas y también, por supuesto, Einstein que vivía a apenas 
unas cuantas millas, en Princeton. Al día de hoy, las grandes universidades de Nueva York proporcionan generosas ayudas a investigadores extranjeros. En realidad, Nueva York siempre ha sido una ciudad global con un carácter internacional. Pero también es un centro comercial crucial en la construcción de la identidad capitalista norteamericana. Una población multicultural de ocho millones de personas que viven en una geografia restrictiva la convierten en la ciudad más intensamente vital del país. He vivido la mayor parte de mi vida en Nueva York o muy cerca de Nueva York. El resultado es que me siento más o menos en casa en cualquier otra ciudad del mundo. Nunca he pensado en Nueva York como en un territorio literario a explorar. No se abre camino en mis libros como un escenario que yo haya elegido sino como la vida. Sencillamente parto de la base de que Nueva York es lo que la vida es. No es un lugar, es la vida (Rendueles, 2003).

Utilizando a New York como telón de fondo, Doctorow nos presenta afectos negativos, obsesiones que torturan, resentimientos que anuncian venganzas, crueldades y despropósitos, y conductas y formas de vida extrañas ${ }^{16}$.

En las novelas del fallecido novelista salen al encuentro del lector personajes logrados, que respiran vida e inspiran intuiciones en él. No nos referimos, claro está, a aquellos que en realidad existieron y a los que Doctorow recurre para delinear el contexto histórico de sus obras. Ni Sigmund Freud en Ragtime, ni el General Sherman en The march requieren de retoques ni acentuaciones para atraernos. Doctorow lo sabía y por eso "los dejó estar", inventando solo algún detalle (un gesto, una conversación, alguna frase o algún encuentro) para ellos.

Pensamos más bien en los personajes totalmente surgidos de su imaginación. Daniel Isaacson Lewin, así como Coalhouse Walker y Billy Bathgate (como también Andrew, su última creación), todos creaciones doctorovianas, impresionan por la lozania de sus perfiles, claramente señalados, por la sensación de realidad que emana de ellos desde las grafias que Doctorow emplea para caracterizarlos, y por la coherencia entre su vida interior y sus actos, que él se preocupó de otorgarles.

Doctorow fue un artesano de la palabra y un experimentador de la exposición. Desde la selección del título de algunas de sus obras hasta el lenguaje (en unos libros articulado, en otros ambiguo cuando no premeditadamente inexacto), es posible reconocer su preocupación por el efecto sugerente y la connotación rica en matices. The book of Daniel alude al texto bíblico ( $E l$ Libro de Daniel, del Antiguo Testamento; The city of God tiene el mismo título que la utopía de San Agustín, La ciudad de Dios); Ragtime hace referencia a un género musical norteamericano 
de fines del siglo XIX y comienzos del $\mathrm{XX}^{17}$, y sirve para anunciar al lector la presencia de Coalhouse Walker, cuyo nombre a su vez rinde homenaje a Michael Kolhaas, el trágico personaje creado por Kleist, el no menos trágico autor alemán. Andrew's brain aparece en una época en la cual las neurociencias fascinan a neófitos e iniciados y prometen desentrañar algunos de los misterios más recónditos de la mente humana.

El Doctorow experimentador de la exposición se revela en la predominancia en algunas de sus obras del monólogo interior en primera persona, interrumpido o enriquecido por otras voces, mientras en otros libros suyos se impone la descripción. No faltan en algunas de sus novelas las reflexiones filosóficas y hasta teológicas (por ejemplo, The city of God). El western distingue a su primera novela, mientras que en otra hay una atmósfera de ciencia-ficción. Big as life roza el género detectivesco.

En toda novela dialogan la acción, la reflexión y el afecto. Ese diálogo puede causar en el lector hilaridad o sorpresa, pero también ira y hasta terror. La calidad de la emoción que ese diálogo despierte depende de la trama que el autor quiere desarrollar, y, para ello, éste debe recurrir a lo mejor, lo más efectivo de su artesanía literaria.

Imaginar amores y odios, ilusiones y desengaños, aventuras y desventuras; idear personajes y poner al trabajo a la imaginación para darles un nombre, una edad, una contextura fisica, un temperamento y un carácter; en seguida mostrarlos al lector solo por medio de la palabra del modo más convincente que sea posible, dotarlos de vida interior y de capacidad de acción, seleccionar, organizar y delinear los ambientes y situaciones en los que ellos vivirán e interactuarán, y, finalmente, elegir las palabras con lo que todo lo anterior será efectivizado: en esto radica la artesanía literaria, que debe ser cumplida con perseverancia y sin desánimo.

Doctorow lo sabía y ejerció esa artesanía literaria con detallismo. Tal vez a eso se deba el largo intervalo entre una y otra obra proveniente de su pluma.

A todo lo anterior Doctorow agregaba algo más: su preferencia -a la que ya nos hemos referido por New York-como el escenario para un buen número de sus obras; y, el empleo de personalidades de la historia norteamericana o mundial como "artistas de reparto".

No es fácil transformar en protagonista a un personaje secundario, pero tampoco es sencillo convertir a un "primer actor" en un "actor de reparto". Valga la pena señalar esto para tratar del empleo por parte de Doctorow de grandes figuras de la historia mundial o de los Estados Unidos en sus novelas. El ejemplo que presentaremos es el del padre del psicoanálisis.

Freud como personaje incidental: eso no solo sería una blasfemia para los psicoanalistas sino también un imposible para todos aquellos que conocen la importancia de su aporte. Freud, que es -qué duda cabe- un 
primer actor, una de las grandes figuras del siglo XX: ¿cómo hacer para que un hombre como él sea reducido a las medidas de un simple mortal, como lo es cada uno de nosotros?

Doctorow lo consigue en Ragtime. Hay una escena que nos parece insuperable:

Freud llegó a Nueva York en el vapor George Washington, de la compañía Lloyd. Le acompañaban sus discipulos Jung $\mathrm{y}$ Ferenczi, ambos más jóvenes que el maestro. En el muelle los recibieron otros dos freudianos jóvenes, el doctor Ernest Jones y el doctor A. A. Brill. El grupo almorzó en la terraza del Hammerstein. Hubo aplausos. Un duo de piano y violín todo la Rapsodia Húngara de Liszt. Todos hablaron acerca de Freud, observándole de continuo para calibrar su estado de ánimo. Comió crema servida en un cuenco. Brill y Jones aceptaron su papel de anfitriones durante esta visita. En los dias que siguieron, enseñaron a Freud el Central Park, el Museo Metropolitano y el Chinatown. Chinos de aspecto felino les observaron desde fuera de tiendas oscuras. Habia vitrinas de cristal con nueces chinas. El grupo asistió a la proyección de una popular película muda en uno de los salones de a cinco centavos la entrada, en el centro de la ciudad. Surgía humo blanco de los cañones de los rifles y hombres con los la- bios pintados y colorete caían de espaldas apretándose el pecho con las manos. Por lo menos, pensó Freud, no hay ruidos. Lo que le oprimía del Nuevo Mundo eran los ruidos. El terrible tamborileo de los caballos y carruajes, el rechinar y ulular de los tranvías, las bocinas de los automóviles. Al volante de un Marmon descapotable, Brill condujo a los freudianos por Manhattan. En un lugar determinado, en la Quinta Avenida, Freud sintió que le estaban observando; levantó la mirada y vio a unos niños que le contemplaban desde lo alto de un autobús de dos pisos (versión castellana de $\mathrm{Rag}$ time, pp. 53-54).

Freud aparece en las lineas previas como un simple mortal, asediado por miradas extrañas e indiscretas y por ruidos insoportables, mientras vagabundea sin norte ni brújula por la inmensa urbe neoyorquina.

Por si esto fuera poco, Doctorow "redondea" la imagen de un Freud casi desamparado:

En realidad no se había acostumbrado a las comidas ni a la escasez de aseos públicos. Creía que aquel viaje había destrozado tanto su estómago como su vejiga (versión castellana de Ragtime: 56)

El argumento de Ragtime bien podría haberse logrado sin la presencia de Freud o de Houdini, el mago mundialmente conocido. Pero Doctorow decidió "adornar" su novela incluyén- 
dolos. Al hacerlo, nos parece, no solo satisfizo ese deseo de ornamentación; también apuntó (y creemos que acertó) a aumentar la sensación de realismo que el lector debía experimentar. Y, además, concedió una suerte de aura de grandeza al drama de Coalhouse Walker Jr., uno de los millones de ciudadanos negros víctimas de exclusiones y vejaciones en los Estados Unidos $^{18}$.

La maestría de este autor permite que sus novelas estén pobladas de personajes logrados que respiran vida. La descripción que Doctorow hace de ellos va acompañada de incisivas exploraciones de su vida interior, todo lo cual estimula sugerentes intuiciones en el lector alerta e imaginativo ${ }^{19}$.

$\mathrm{Su}$ estilo es original: algunos de sus libros no son de lectura fácil pues demandan un conocimiento histórico no siempre frecuente. Ese es el caso de Ragtime. Freud, evidentemente, no requiere presentación, pero no sucede lo mismo con otros "primeros actores" que Doctorow hace aparecer en las páginas de esta obra: el propio Houdini, Booker T. Washington ("en esta época el negro más famoso del país"; versión castellana de Ragtime: 340), ¿quiénes fueron?

El lector se perderá en medio de tantas luminarias, porque, aparte de Henry Ford, ¿qué sabe él de Evelyn Nesbit, una modelo que jugó un rol importante en un proceso judicial que recibió gran atención en aquellos años, o de Emma Goldmann, anarquista y heroina del movimiento laboral norteamericano? ¿o del propio J.P.

\section{Morgan?}

Ya lo hemos dicho y ahora lo repetimos: Doctorow es un experimentador de la palabra y de la trama. En unas obras predomina el monólogo, en otras la reflexión filosófica y hasta teológica. $\mathrm{Y}$ hay algunas que se acercan al género detectivesco.

Hay un diálogo entre la acción y la reflexión, un contrapunto entre lo que sucede en el exterior y lo que se vivencia en el mundo privado de cada cual ${ }^{20}$; y se percibe una tensión entre lo que en verdad ocurrió y lo que Doctorow decide que suceda con los personajes que él recrea a partir de los protagonistas de los hechos que la historia registra.

No se podía predecir cuál sería el estilo de su próxima novela. En unos casos aparecía el monólogo interior, en otros la obra presentaba varias voces ${ }^{21}$

Son, nos parece, esos los rasgos que hacen de Doctorow un escritor ameno al par que exigente, localista (por su preferencia por New York) y sin embargo universal (por los problemas de la condición humana que él aborda), estudioso de la historia pero al mismo tiempo un afortunado manipulador de los hechos.

Esto último, su interés por la historia de New York y de los Estados Unidos, es una singularidad de su obra. Doctorow emplea la historia en sus libros, pero su empleo es muy personal, muy liberal. En Ragtime aparecen personajes históricos de carne y hueso, como Sigmund Freud durante su única y decepcionante visita a los Estados Unidos, o como Francisco 
Fernando, el heredero al trono del Imperio Austro-Húngaro cuya muerte sería el detonante de la Primera Guerra Mundial. Hay más, pero con ellos dos basta para sustentar lo que decimos.

Doctorow los usa, los manipula podriamos decir, para matizar y enriquecer sus libros. A veces esa manipulación raya en la desmesura. Como hemos dicho, Homer y Langley existieron en realidad y fallecieron en los años 1940. En la novela que tiene por título sus nombres, Doctorow los "hace vivir" unos veinte años más de lo que realmente vivieron.

Esta tendencia a la manipulación de la historia de Doctorow fue objeto de duras críticas ${ }^{22}$. Sin embargo, eso que sería inaceptable en el trabajo de un historiador, se justifica en el taller del literato. Recordemos si no, lo que afirma Nabokov (2010):

La literatura es invención. La ficción es ficción. Calificar un relato de historia verídica es un insulto al arte y a la verdad. Todo gran escritor es un gran embaucador, como lo es la architramposa naturaleza (35).

Doctorow defendió su uso liberal de la historia. Al fin y al cabo, él no era un historiador ni un cronista, sino un literato.

No cabe duda que Doctorow manipulaba personajes y situaciones a su gusto, o mejor dicho, según las necesidades de la trama que deseaba desarrollar. Esto, que en el mundo de periodismo habria sido imperdonable, él lo justificaba y defendía. En un artículo titulado "Notes on the history of fiction", publicado en el 2006 en The Atlantic, escribió:

Desde una perspectiva histórica hubo algo así como una guerra de Troya. De hecho tal vez haya habido varias guerras de Troya. Pero la guerra sobre la cual escribió Homero es la que nos fascina porque es ficción [...] ¿Quién cambiaría la Iliada por el registro histórico ${ }^{23}$

Pero no solo los literatos mezclan historia y ficción. También lo hacen los cultores de otras artes. En la música, por ejemplo, Chaikovski "reconstruye" la invasión napoleónica de Rusia y la derrota de los invasores en su Obertura Solemne 1812. En la escultura, en Lima, el escultor Victorio Macho (1887-1966) nos ofrece una imagen de Miguel Grau, el héroe peruano de la Guerra del Pacífico, tal como él lo imagina y no necesariamente tal como él fue. Picasso nos ofrece su visión personal del bombardeo de Guernica en el mural que lleva su nombre.

$Y$ es que en el arte puede estar permitido lo que está prohibido en la realidad y lo que no se admite en la ciencia. Los cuadros de Salvador Dalí son un buen ejemplo de ello. La lógica nunca ha sido la mejor consejera de los artistas, excepto tal vez los arquitectos.

$\mathrm{Si}$, como hemos dicho, en las novelas de Doctorow podemos encontrar personajes que resultan de interés para el estudio y la reflexión psicológica, queda un último tema: el de la psicología de su autor.

Comencemos por la generalizada 
imagen del escritor, del novelista en particular, como alguien que lleva una vida en la cual la psicopatología está presente, lo que se conoce como " madgenius stereotype" (Kaufman et al. 2006). Una imagen en la que calzan perfectamente William Faulker, John Cheever, F. Scott Fitzgerald y William Saroyan, que lucharon contra el alcoholismo (Silvia \& Kaufman, 2010).

Doctorow no encaja en el mad-genius stereotype. No se le conoció psicopatologías, manias y excentricidades que, tal vez, le hubieran concedido un aura de "tocado por el fuego" (Jamison, 1993), algo que podría haber realzado su imagen y tal vez aumentado el número de sus seguidores. Solo sabemos que era un "heavy smoker", lo cual sin duda determinó el cáncer a los pulmones que lo llevó a la tumba ${ }^{24}$.

Los elementos autobiográficos están presentes en muchos de sus trabajos $^{25}$. Como también es evidente la intensa preocupación que Doctorow experimentó por todo lo que fuera injusticias e inequidades ${ }^{26}$. ¿Tiene eso que ver con lo que vivió?

No olvidemos que Doctorow provenía de una familia cuyos antecesores habian dejado Rusia para trasladarse a los Estados Unidos. La emigración es siempre la búsqueda de un destino mejor, y Rusia no era (y aun no lo es) el mejor lugar para vivir.

"La historia rusa ha sido una historia de sufrimiento y humillaciones", afirma con razón Steiner (2009: 227). La historia rusa es, obviamente, la historia de los rusos, de cada uno de ellos. No ha sido una vida fácil la de los rusos, en lo menos que se puede decir. Desde Iván El Terrible hasta Stalin, la injusticia desembozada, el autoritarismo aplastante, los derramamientos de sangre y la incertidumbre acerca del hoy y del mañana en la vida de cada individuo, han sido los compañeros de los rusos. También hoy, como lo demuestra Svetlana Alexievich, la más reciente Premio Nobel de Literatura, con su libro Secondhand-Zeit. Leben auf den Trümmern des Sozialismus (Alexievich, 2013)

Y dentro de los habitantes de ese inmenso país, la población judía estuvo siempre expuesta a maltratos aún mayores. ¿Es posible imaginarnos al niño y adolescente Doctorow escuchando a sus abuelos acerca de los avatares e injusticias que los obligaron a emigrar?

Tal vez esas experiencias y recuerdos familiares fueron las que sensibilizaron a Doctorow con respecto a las inequidades que por lo demás abundaban en la sociedad norteamericana.

Concluida la existencia de este autor será, como siempre, el tiempo el que aquilatará su obra.

Podría, por cierto, suceder con ella lo ocurrido con la de otros escritores, aclamados en su momento y olvidados hoy. ¿Quién recuerda hoy a Roger Martin Du Gard? ¿qué obra de Maurice Maeterlinck se lee en nuestros dias, excepto La vida de las hormigas y La vida de las abejas, en las que él despliega una fantasía que fascina a lectores infantiles pero escandaliza los entomólogos? ¿qué sabe el lector de 
hoy de Anatole France, Sigrid Unset y Grazia Deledda?

Los temas que han estado en la mira del Doctorow novelista, la justicia y la ciudad de New York dos de ellos, podrian perder actualidad en lo que va de este siglo, que ni siquiera ha alcanzado su primer cuarto de existencia. ¿Por qué no imaginarnos que en unos veinte o treinta años ciudades como Shangai, Sao Paulo o Sidney terminen compitiendo o tal vez desplazando a la metropóli neoyorquina como lugar de interés y de inspiración para novelistas o poetas?

Sea cual fuere el destino que el tiempo tenga reservado al legado literario de Doctorow, arriesgamos al menos una valoración provisional (y, por supuesto, personal) del mismo, diciendo que sus libros retratan momentos críticos de la sociedad estadounidense. La Guerra de la Secesión, los albores del siglo XX.

Doctorow como retratista, no como fotógrafo. Lo que el lector encuentra en sus libros no es una imagen fidedigna de lo ocurrido y de sus protagonistas, sino un retrato. Por eso se los lee, por eso se los busca. Ese es su "valor agregado".

Pues, mientras el trabajo del fotógrafo se resume grosso modo en un click que perenniza el instante, el retratista aspira a capturar la esencia de lo que retrata, al mismo que comuni- car a los otros el impacto que lo sucedido ha tenido en su sensibilidad. Al fin y al cabo, existe entre el retratista y aquello que desea retratar una relación personal, única, que se expresará de todos modos en el retrato (Matt, 2008).

Doctorow como retratista enriquece la realidad recurriendo a todo lo que le es permitido a un autor de novelas: la fantasía en primer lugar, pero además la abierta manipulación de personas y contextos, el juego de palabras, la exposición a veces precisa y en otras ocasiones indefinida de protagonistas, interlocutores y lugares, dejando al lector alerta y sensitivo la tarea de hilvanar los hechos y adivinar destinos - según su sentir e intuir- para ofrecer un final, "su final" a lo leído.

En el empleo de todos estos recursos y otros más, Doctorow desliza en unos casos y en otros se sumerge decididamente en reflexiones acerca de la condición humana.

Andrew's brain, su última obra, es también un retrato, tal vez el más ambicioso de todos los que llevó a cabo Doctorow. Ya no el retrato de su querido New York ni de hechos históricos registrados en libros o preservados en la memoria colectiva. El retrato contenido en Andrew's brain es el de una realidad inconmensurable, inasible, siempre cambiante, la más misteriosa de todas las realidades: el retrato de la subjetividad del hombre del siglo XXI. 
Notas

1 Así firmaba sus libros, con solo las iniciales de sus nombres, Edgar Lawrence.

${ }^{2}$ Doctorow llegó a ser propuesto como candidato al Premio Nobel de Literatura. Ante la pregunta "Usted, junto con Don DeLillo, Philip Roth y Paul Auster completa la lista de los eternos aspirantes al Nobel de Estados Unidos, un país que no recibe ese premio desde 1993", respondió:

"A ese respecto, solo tengo una cosa que decir: no creo que el Comité Nobel, tal y como está constituido en la actualidad, tenga ninguna intención de darle un premio a un autor de Estados Unidos. Creo que es una cuestión de ira. No sé si es ira desde el punto de vista político o económico, o porque el nuevo orden imperial de este país está deprimiendo a todo el mundo. El Comité es bastante claro a ese respecto. No tengo más que añadir" (Doctorow 2014).

3 Welcome to hard times (1960; El hombre malo de Bodie, 1981, Cómo todo acabó y volvió a comenzar, 2012), Big as life (1966), The book of Daniel (1971, El libro de Daniel, 1979), Ragtime (1975; con el mismo título en castellano, 1976), Loon Lake (1980, El lago, 1981), World's fair (1985; La feria del mundo 1991), Billy Bathgate (1989; con el mismo título en castellano, 1990), The Waterworks (1994; El arca de agua, 1995), City of God (2000; La ciudad de Dios, 2002), The march (2005; La gran marcha, 2006), Homer \& Langley (2009; con el mismo título en castellano, 2010), Andrew's brain (2014; El cerebro de Andrés, 2014).

4 La 15. edición de The New Encyclopedia Britannica (1995) contiene una entrada dedicada a Philip Roth (pg. 201 del volumen 10, 33 lineas), en tanto que ignora a Doctorow. Mecanismos internos, libro de Coetzee (2009), incluye ensayos sobre William Faulkner, Saul Bellow, Arthur Miller y Philip Roth; Doctorow no aparece. Por último, el voluminoso y bastante completo Diccionario de literatura universal (Barcelona, Océano, 2006) dedica a Doctorow 54 líneas (pg. 301), igual número que las dedicadas a Don DeLillo (pg. 286). Por contraste Roth recibe 60 lineas (pp. 894-895, incluyendo además una foto), Pynchon 45 (pg. 840, aparte de una foto), y Paul Auster 49 (pg. 76, además de una foto). Norman Mailer los supera a todos con 94 líneas (más foto; pg. 631). James Baldwin sigue a Mailer (77 líneas y foto; pp. 84-85). Mailer y Baldwin también aparecen en la ya mencionada edición de la Britannica: el primero con 70 líneas y foto (vol. 7; pp. 705-706), el segundo con 60 (vol 1; pg. 828, con foto).

5 Rosenzvaig (2009) anota que la locura es el alimento preferido de la tragedia griega.

6 En su Curso de psiquiatría (Delgado 1969), Honorio Delgado considera valiosas además,

"las descripciones de los grandes literatos que sufren y estudian sus flaquezas y anormalidades: Dostoievski, Amiel, Rousseau, Grillparzer, Hebbel, Cellini, Leopardi, De Quincey, Baudelaire, Maupassant, Proust y tantos otros" (pg. 29).

7 El protagonista está basado en Michael Meeropool, el hijo de los ejecutados Julius y Ethel Rosenberg.

8 La recepción de esta obra fue excelente (véase por ejemplo Lehmann-Haupt 1971). En 1983 fue llevada al cine con el título de Daniel, por Sidney Lumet (1924-), un director que había producido varias películas previas con temas políticos.

9 Arthur Miller (1915-2005) dio a la luz en 1953 Las brujas de Salem, "donde trazó un paralelo entre los procesos inquisitoriales de 1692 y la cruzada anticomunista del senador MacCarthy", se puede leer en el Diccionario de Literatura Universal (2006; pg. 690).

${ }^{10}$ Inclusive Alfred C. Kinsey, cuyas investigaciones sobre la sexualidad humana son entre tanto referencias rituales en todo trabajo sobre el área, fue objeto en los años 50 de duros ataques, acusado de ayudar al comunismo a minar la moralidad sexual y el carácter sacrosanto de los hogares norteamericanos (Jones 1997).

${ }^{11} \mathrm{El}$ destino de los Rosenberg ha sido tema de interés no solo para Doctorow sino para 
otros literatos norteamericanos. Robert Coover (1932-) publicó The public burning (1977), Tony Kuschner (1956-) trata de aspectos de este caso en Angels in America: a gay fantasia on national themes (1993), así como Sylvia Plath (1932-1963) en The bell jar (1963).

12 No solo la literatura tiene un efecto catártico; también la pintura (véase Klibansky et al. 2013). Y, por supuesto, la música, como lo demuestran la Sinfonía Patética de Chaikovski, y el Concierto para piano nro. 2 en do menor, opus 18, de Rachmaninov. Como lo señala Goldberg (2007), el arte y la música son "herramientas esenciales para alcanzar y mantener la buena forma mental” (pg. 301).

${ }^{13}$ Para los inmigrantes europeos que llegaron a los Estados Unidos en el siglo XIX, New York era "la ciudad", la primera impresión de la tierra prometida. Tres cuartos de los más de 667 mil inmigrantes ingresaron a los Estados Unidos por el puerto de New York; un porcentaje semejante de los 4.242.000 de inmigrantes en los años 1840 y 1850 también ingresaron a los Estados Unidos por New York (Howe 2007).

${ }^{14}$ La Feria Mundial de New York de 1939/1940 pretendia ofrecer a sus visitantes una mirada al futuro y alrededor de 45 millones de personas la visitaron yendo a Flushing Meadows, Queens.

${ }^{15}$ Para Robertson (1992), la novela de Doctorow ofrece una narrativa de la imagen de la Feria que se hace una persona de clase media norteamericana, agregando que la novela "muestra como cada individuo puede moldear las experiencias que ofrece la cultura de masas adaptándola a sus propias necesidades, y así hallando placer dentro de dicha cultura mientras al mismo tiempo ignora o se subleva con respecto a las intenciones de los diseñadores de ella” (pg. 36).

${ }^{16} \mathrm{El}$ empleo de New York como telón de fondo ha sido la causa para que algunos consideraran a Doctorow "un escritor neoyorquino", esto es un cronista de las grandezas, peripecias, vicisitudes y miserias de los habitantes de esa metrópoli, devaluando así el significado de su obra, al concederle solo una significación local.

Lo cierto es que ciudades como New York, Tokio, México DF o Sao Paulo, cada una con millones de habitantes rodeados del anonimato, son verdaderos mundos en sí mismas, en los cuales la realidad de los hechos supera en muchos casos largamente a lo que la fantasía pueda crear. El drama humano en el siglo XX no ocurre más en el campo. Su escenario hoy es la ciudad, especialmente la gran ciudad.

Es por ello que algunas obras literarias tienen como protagonistas no a seres individuales, sino a grandes ciudades, como ocurre con Berlin Alexanderplatz, de Alfred Döblin (1929), Manhattan Transfer, de John Dos Passos (1925), y, en el contexto latinoamericano, La región más transparente, de Carlos Fuentes (2008).

${ }^{17}$ En la edición castellana de Ragtime aparece la siguiente nota referida al significado de este término:

"El ragtime es casi el polo opuesto al blues. Se trata de un estilo pianístico formal, casi neoclásico, con unos recursos rítmicos muy limitados. Dio al jazz un sentido crucial de melodia, de forma y, probablemente de armonía. En los Estados Unidos el ragtime se escuchaba ya con insistencia en muchos lugares hacia 1880, pero sus centros creativos fueron, primero, Sedalia y Missouri, y más tarde St., Louis, siendo su compositor más importante Scott Joplin (1868-1917). En el ragtime ya existía la improvisación, así como ciertos modos de improvisación escritas, pero la composición era su base más importante. El periodo de mayor popularidad de este género puede situarse en los primeros años de nuestro siglo, hasta 1920. A partir de aquí, predomina claramente el jazz, hasta el punto de que el escritor F. Scott Fitzgerald, al hablar en tono memorialístico de la década de 1920, la denominará "Jazz Age" ("Nota a la edición castellana" de Ragtime, México DF, Grijalbo, 1976, pg. 9).

${ }^{18}$ Se podría suponer, por último, que Doctorow tenía una proclividad a emplear personajes históricos como un divertimento. Hombre de muchas y variadas lecturas, es proba- 
ble que quisiera emplear lo leído para un "enriquecimiento" de sus obras, llevando al lector por un camino en el cual lo sucedido va de la mano de lo imaginado, la verdad "tal cual ella fue" está unida a la verdad "tal como el autor quiere que sea", sorprenden al lector. En literatura hay muchos ejemplos de divertimentos. Se nos ocurre solo mencionar uno: "Un discurso para probar la antigüedad de la lengua inglesa", de Swift (2013).

${ }^{19}$ Sobre el particular Doctorow (1993) escribe en "Documentos falsos":

"La literatura de ficción no es simplemente un medio racional de discurso. Le proporciona al lector algo más que mera información. De las palabras de la narración surgen conceptos complejos, indirectos, intuitivos y no verbales, y mediante una transacción ritual entre el lector y el escritor, se genera en aquél una emoción aleccionadora a partir de la ilusión de sufrir una experiencia que no es la suya. Una novela es un circuito impreso a través del cual fluye la energía de la vida del lector" (pg. 193).

20 "En sus novelas se pueden encontrar reflexiones, pensamiento, acción, compasión y lucidez a partes iguales, siempre mostrados de manera estrictamente literaria. Hasta el punto de que sus variados enfoques e historias siempre fueron acompañados de una estética específica para cada uno de ellos. En este aspecto, podría dar sensación de dispersión, sí, pero nunca de incoherencia”, escribe Guelbenzu (2015).

${ }^{21}$ Eso sucede por ejemplo en World's fair, en la cual los relatos corren a cargo de varias personas. En una entrevista, el novelista señala que fue compuesta para leerse como si se estuviera escuchando la grabación de lo que los protagonistas relatan (Doctorow 1986).

${ }^{22}$ Véase por ejemplo la formulada por John Updike (2005) al inicio de su comentario crítico, por lo demás muy positivo, de The march.

${ }^{23}$ También en el ensayo "Documentos falsos" Doctorow (1993) reivindica el poder de la ficción y cuestiona la autoridad atribuida a los hechos. La distinción que se hace entre "ficción" y no-ficción" no pasa de ser, según él, una ilusión y proviene de de la tradición occidental de separar la razón de los sentimientos. John Williams (1996) considera los planteamientos propuestos en este ensayo como centrales para entender la obra de Doctorow.

${ }^{24}$ Pablo Pardo, en una entrevista aún reciente, escribe:

"Su vida es normal hasta el aburrimiento. Fue profesor de universidad durante décadas, impartía un curso en la Universidad de Nueva York titulado "El oficio de la ficción", en el que despiezaba obras literarias para ver "cómo funcionan, en qué funcionan, de dónde sacan su autoridad, etcétera” (Doctorow 2014).

${ }^{25}$ En el comentario que hace David Leavitt de World's fair en el New York Times (10.11.1985), señala que esta obra es un peculiar híbrido de novela y memorias, y anota, seguidamente, lo siguiente:

"El héroe, como Doctorow, se llama Edgar, y crece en el Bronx de los años 1930; sus padres, como los de Doctorow, se llaman Rose y David; su hermano, como el hermano del autor, Donald".

${ }^{26}$ La preocupación por la justicia y por la injusticia se manifestó también en la toma de posición de Doctorow con respecto al informe de Kenneth Starr sobre el caso Lewinsky que hizo tambalear al gobierno del presidente Clinton. Doctorow (1998) lo comparó con el caso de los Rosenberg y con la cacería de las brujas de Salem. 


\section{REFERENCIAS}

Alexievich, S. (2013). Secondhand-Zeit. Leben auf den Trümmer des Sozialismus. Berlin: Hanser [traducción del ruso]

Bloom, H., ed. (2004). E. L. Doctorow/Ragtime. Broomall, PA: Chelsea House Publishers.

De Rivarol, A. (2012). Vom Menschen. Gedanken und Maximen. Portraits und Bonmots. Berlin: MSB Matthes \& Seitz Berlin Verlagsgesellschaft [ edición de U. Kunzmann].

Delgado, H. (1969). Curso de psiquiatría. Barcelona: Científico-Médica.

DeRosa, A. (2009). Apocryphal trauma in E. L. Doctorow's The book of Daniel. Studies in the Novel, 41 (4), 468-488.

Doctorow, E. L. (1986). The art of fiction. The Paris Review, invierno, nro. 101 [entrevista a cargo de G. Plimpton].

Doctorow, E. L. (1993). Documentos falsos. En: Doctorow, E. L., Poetas y presidentes, Barcelona, Muchnik Editores, 193-212.

Doctorow, E. L. (1998). Has Starr humiliated us all? The New Yorker, edición del 12 de octubre, pg. 29.

Doctorow, E. L. (2014). “Juzga al lector". El Mundo, 23 de octubre [entrevista por P. Pardo] [http://www.elmundo.es/cultura/2014/10/23/5448ba10ca4741 f0708b456f.html, recuperado el 25.10.2015].

Goldberg, E. (2007). La paradoja de la sabiduría. Cómo la mente puede mejorar con la edad. Barcelona: Crítica.

Guelbenzu, J. M. (2015). E. L. Doctorow, el cronista del siglo más convulso de los EE UU. El País, edición del 22 de julio.

Guijarro González, J. I. (2001). Las dos mitades de la "Gran Manzana": Nueva York en las novelas de E. L. Doctorow de los años 80. En: Marí, P.; Matas Llorente, M.; Del Mar Gallego, M.; Toda, M. A.; Guijarro González, J. I. \& Espejo, R., Imágenes de la gran ciudad en la novela norteamericana contemporánea, Sevilla, Universidad de Sevilla, 35-62.

Hobsbawm, E. (1996). Historia del siglo XX. 1914-1991. Barcelona: Crítica.

Jamison, K. R. (1993). Touched with fire: manic-depressive illness and the artistic temperament. New York: Free Press.

Jones, J. H. (1997). Alfred C. Kinsey. A public/private life. New York - Londres: Norton.

Klibansky, R.; Panofsky, E. \& Saxl, E. (2013). Saturn und Melancholie. Studien zur Geschichte der Naturphilosophie und Medizin, der Religion und der Kunst. Frankfurt: Suhrkamp.

Leavitt, D. (1985). World's fair. New YorkTimes, edición del 10 de noviembre.

Lehmann-Haupt, Ch. (1971). The book of Daniel. New York Times, edición del 7 de junio. 
Matt, P. v. (2008). ... fertig ist das Angesicht. Zur Literaturgeschichte des menschlichen Gesichts. Munich: Deutscher Taschenbuch Verlag.

Medrano, J. (2011). Revisión de Homer y Langley, de E. L. Doctorow. Revista de la Asociación Española de Neuropsiquiatría, 110 (31), 376-379.

Nabokov, V. (2010). Curso de literatura europea. Buenos Aires: Del Nuevo Extremo, RBA.

Oates, C. J. (1969). Them. New York: Vanguard Press.

Pamuk, O. (2009). Otros colores. Buenos Aires: Mondadori.

Parks, J. (1991). E. L. Doctorow. New York: Continuum.

Rendueles, C. (2003). E. L. Doctorow ¿la novella? Al fondo a la izquierda. http://www.rebelion.org/hemeroteca/cultura/031008ed.htm ; recuperado el 6.10.2015).

Robertson, M. (1992). Cultural hegemony goes to the fair: the case of E. L. Doctorow's World's Fair. American Studies, 33 (1), 31-44.

Rosenzvaig,M. (2009). El teatro de la enfermedad. Buenos Aires: Biblos.

Talbot, D. (2008). La conspiración. La historia secreta de John y Robert Kennedy. Barcelona: Crítica.

Kaufman, J. C.; Bromley, M. L. \& Cole, J. C. (2006). Insane, poetic, lovable: creativity and endorsement of the "Mad Genius" stereotypes. Imagination, Cognition, and Personality, 26, 149-161.

Silvia, P. \& Kaufman, J. C. (2010). Creativity and mental illness. En: Kaufman, J. C. \& Sternberg, R. J., eds., The Cambridge handbook of creativity, New York, Cambridge University Press, 381-394.

Steiner, G. (2009). George Steiner en The New Yorker. Madrid: Siruela.

Swift, J. (2013). Un discurso para probar la antigüedad de la lengua inglesa”. En: Swift, J., De lengua, estilo, conversación y bagatelas, Santiago, Chile, Tajamar Editores, 139-151 [original circa 1716-1720; introducción, traducción y notas de P. Oyarzún].

Updike, J. (2005). A cloud of dust. E. L. Doctorow's "The march". The New Yorker, edición del 12 de setiembre.

Van der Merwe, P. \& Bekker, I. (2015). Doctorow's fictional autobiography: World's fair (1985) as a carnivalesque Bildungsroman. Literator 36 (2), 1-9. 